\title{
ОСОБЕННОСТИ АДМИНИСТРАТИВНО-ПРАВОВОГО РЕГУЛИРОВАНИЯ ГОСУДАРСТВЕННО-СЛУЖЕБНЫХ ОТНОШЕНИЙ ПРИ ИЗМЕНЕНИЯХ В СТРУКТУРЕ ФЕДЕРАЛЬНЫХ ОРГАНОВ ИСПОЛНИТЕЛЬНОЙ ВЛАСТИ
}

\begin{abstract}
Аннотация: В статье исследуется специфика правового регулирования государственно-служебных отношений при изменениях в структуре федеральных органов исполнительной власти. В частности, освещены вопросы приёма на государственную службу при создании новых, реорганизации и упразднении действующих федеральных органов исполнительной власти. Особое внимание уделяется соблюдению процедуры уведомления гражданского служащего о предстоящем сокращении должности, возможности проведения внеочередной аттестаиии, а также порядка предложения имеющихся вакансий, в том числе с использованием сервисов Федерального портала государственной службы и управленческих кадров При проведении исследования использовались формально-юридический и структурно-функииональный методы, которые обеспечили комплексное изучение проблематики правового регулирования государственно-служебных отношений при изменениях 8 структуре федеральных органов исполнительной власти. В результате анализа установлено, что на фоне финансово-экономического кризиса постоянно предпринимаются усилия по оптимизации действующего аппарата государственного управления. Причём процесс проведения организачионно-штатных мероприятий, особенно, если он связан с сокращением должностей государственной службы либо упразднением государственного органа, неизбежно связан обжалованием действий представителя нанимателя в суде.
\end{abstract}

Ключевые слова: Государственная служба, Увольнение, Сокращение должности, Реорганизаџия, Министерство, Административная реформа, Государственные гарантии, Уведомление об увольнении, Государственный служаший, Правовой статус.

Abstract: This article examines the specifics of the legal regulation of public service relationships during the transformations in the structure of the federal executive authorities. In particular, it addresses the issues of admission to the public service while creating new, reorganizing and abolishing of the existing federal executive authorities. Particular attention is paid to the procedure of notification of civil servant of the impending reduction of positions, the possibility of holding an extraordinary examination, and offering available positions, especially with the use of the services of the Portal of the federal public service and administrative personnel. The study uses legal and structural methods that provide a comprehensive study of the problems of legal regulation of public-service relationships during transformations in the structure of the federal executive authorities. The analysis revealed that during financial and economic crisis, efforts are constantly made to optimize the existing apparatus of government. Moreover, the process of organizational optimization, especially if it is connected with reduction in civil service posts or the abolition of the state authority, inevitably leads to the appeal of actions of the employer in court.

Keywords: Notice of dismissal, Government guarantee, Ministry, Administrative reform, Reorganization, Reduction of the post, Dismissal, Public service, Public servant, Legal status.

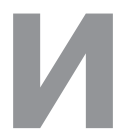

зменения в структуре федеральных органов исполнительной власти направлены на оптимизацию аппарата государственного управления и неминуемым образом затрагивают государственных служащих, состоящих в государственно-служебных отношениях с реорганизуемыми либо упраздняемыми органами. С точки зрения структуры федеральных органов исполнительной власти интерес представляет также исследование особенностей государственно-служебных отношений при образовании нового федерального органа исполнительной власти, поскольку возникает объективная потребность в короткий промежуток времени обеспечить вновь созданную структуру государственными служащими, которые будут соответствовать необходимым квалификационным требованиям и обеспечивать выполнение функций органа власти.

После административной реформы 2004 года в течение последующих лет в структуре федеральных органов исполнительной власти было образовано 24 новых федеральных органа исполнительной власти, в том числе 5 федеральных министерств, а в результате преобразований существующих органов исполнительной власти - 25 федеральных органов 
исполнительной власти, в том числе 12 федеральных министерств. Указанные цифры свидетельствуют об объективной потребности всестороннего исследования и комплексного административно-правового обеспечения возникающих правоотношений [1].

Процесс возникновения федерального органа исполнительной власти предусматривает на данный момент издание указа Президента Российской Федерации, на основании которого утверждается положение о данном органе (в зависимости от подведомственности актами Президента Российской Федерации либо Правительства Российской Федерации).

При создании нового органа власти возникает необходимость единовременного подбора достаточно большого количества государственных служащих. Так, например, образованному в соответствии с указом Президента Российской Федерации от 13.09.2004 г. № 1168 Министерству регионального развития Российской Федерации (которое было упразднено 8 сентября 2014 года указом № 612) постановлением Правительства Российской Федерации от 28.09.2004 г. № 501 «Вопросы Министерства регионального развития Российской Федерации» предусматривалась штатная численность в 240 единиц, которая в редакции указанного постановления от 26.01.2005 г. (через 120 дней) была увеличена до 352 единиц. Таким образом, с целью обеспечения функционирования указанного органа власти возникла потребность подбора указанного количества служащих.

Положение о Минрегионе России было утверждено Постановлением Правительства Российской Федерации от 26.01.2005 г. № 40, п. 10.5 которого устанавливалось, что Министр утверждает структуру и штатное расписание центрального аппарата Министерства в пределах установленных Правительством Российской Федерации фонда оплаты труда и численности работников, смету расходов на его содержание в пределах утвержденных на соответствующий период ассигнований, предусмотренных в федеральном бюджете.

Причем процесс поступления на государственную службу в отношении части вакансий вновь создаваемого органа связан с временными затратами на проведение конкурсных мероприятий в порядке, определённом указом Президента Российской от 01.02.2005 г. № 112 «О конкурсе на замещение вакантной должности государственной гражданской службы Российской Федерации», а также с оформлением допуска к сведениям, составляющим государственную тайну, в соответствии с Инструкцией о порядке допуска должностных лиц и граждан Российской Федерации к государственной тайне, утверждён- ной Постановлением Правительства Российской Федерации от 06.02.2010 г. № 63.

На данный момент несомненную помощь в подборе государственных служащих во вновь создаваемые органы исполнительной власти оказывает федеральный портал государственной службы и управленческих кадров. В соответствии с Положением о данной федеральной государственной информационной системе, утверждённым постановлением Правительства Российской Федерации от 4 марта 2011 г. № 149, основной задачей открытой части портала является обеспечение доступа к информации о государственной и муниципальной службе и вакантных должностях, а закрытой части портала - информационно-методическое обеспечение кадровой работы, информационно-технологическое обеспечение принятия организационно-управленческих решений по кадровым вопросам. Таким образом, Портал представляет собой кадровый инструмент, позволяющий оперативно осуществить подбор на вакантные должности государственной службы лиц, отвечающих необходимым квалификационным требованиям.

При утверждении структуры вновь создаваемого федерального органа исполнительной власти, планировании его штатного расписания особую системообразующую роль играет постановление Правительства Российской Федерации от 05.11.1995 г. № 1094 (ред. от 27.02.2013) «О структуре центрального аппарата федеральных органов исполнительной власти», в соответствии с которым руководителям федеральных органов исполнительной власти рекомендуется исходить из того, что количество ведущих должностей государственных служащих не должно превышать 10 процентов, а старших - 40 процентов общей численности работников этих органов. Также постановлением предусматривается, что штатная численность департамента не может быть менее 35 единиц, управления - менее 20 единиц, отдела - менее 10 единиц, отдела в составе департамента (управления) - менее 5 единиц. При этом в структуру департамента и управления не могут входить менее 3 отделов.

Как отмечалось выше, часть органов исполнительной власти не создаётся впервые, а возникает в результате преобразования существующих органов власти. Причём такие преобразования могут иметь разную направленность: преобразование федерального агентства в федеральное министерство (например, в соответствии с указом Президента Российской Федерации от 01.11.2013 г. № 819 Федеральное агентство по строительству и жилищно-коммунальному хозяйству было преобразовано в Министерство строительства и жилищно-коммунального хозяй- 
ства Российской Федерации); разделения одного федерального министерства на два самостоятельных ведомства (например, в соответствии с указом Президента Российской Федерации от 21.05.2012 г. № 636 Министерство здравоохранения и социального развития Российской Федерации было преобразовано в Министерство здравоохранения Российской Федерации и Министерство труда и социальной защиты Российской Федерации) и др.

При проведении организационно-штатных мероприятий, связанных с преобразованием в системе федеральных органов исполнительной власти, ориентиром выступает один из базовых принципов законодательства о государственной гражданской службе - стабильность. В контексте реорганизации федеральных органов исполнительной власти данный принцип предусматривает сохранение гражданских служащих путём перераспределения кадров внутри единой системы государственной службы с целью сохранения квалифицированных и опытных служащих в государственном аппарате.

С учётом того, что изменение структуры федеральных органов исполнительной власти осуществляется посредством издания указов Президента Российской Федерации, в их тексте зачастую содержится поручение о сохранении кадрового потенциала упраздняемого или реорганизуемого органа (например, указ Президента Российской Федерации от 02.02.2016 г. № 41 «О некоторых вопросах государственного контроля и надзора в финансово-бюджетной сфере»), но также может содержаться поручение по сокращению передаваемой штатной численности (например, указ Президента Российской Федерации от 05.04.2016 г. № 156 «О совершенствовании государственного управления в сфере контроля за оборотом наркотических средств, психотропных веществ и их прекурсоров и в сфере миграции», которым предусмотрена передача МВД России штатной численности ФМС России с сокращением на 30 \%).

Государственно-служебные отношения, возникающие при проведении реорганизационных мероприятий в структуре федеральных органов исполнительной власти, непосредственно урегулированы ст. 31 Федерального закона от 27.07.2004 г. № 79-Ф3 «О государственной гражданской службе Российской Федерации». При реорганизационных мероприятиях по общему правилу государственно-служебные отношения с гражданским служащим продолжаются в случае предоставления с его письменного согласия иной должности гражданской службы в том же государственном органе (например, в случае его переименования или преобразования) или в государственном органе, которому передаются функции упраздняемого государственного органа, либо в другом государственном органе с учётом уровня квалификации, специальности, направления подготовки, продолжительности стажа гражданской службы или работы по специальности, направлению подготовки, либо с учётом уровня его профессионального образования, продолжительности стажа гражданской службы или работы по специальности, направлению подготовки при условии получения им дополнительного профессионального образования, соответствующего области и виду профессиональной служебной деятельности по предоставляемой должности гражданской службы.

Организационно-штатные мероприятия предусматривают процедуру персонального уведомления государственного гражданского служащего о сокращении должности, которая должна быть осуществлена не менее чем за два месяца до увольнения. При этом в течение указанного периода представителем нанимателя осуществляется ряд мероприятий, направленных на защиту прав гражданских служащих.

В соответствии с ч. 3 ст. 31 в течение двух месяцев с момента уведомления государственного служащего о предстоящем сокращении должности в государственном органе может проводиться внеочередная аттестация. Причём принятие решения о проведении внеочередной аттестации является правом представителя нанимателя, а не его обязанностью.

Необходимо отметить, что аттестации не подлежат гражданские служащие, проработавшие в занимаемой должности гражданской службы менее одного года; достигшие возраста 60 лет; беременные женщины; находящиеся в отпуске по беременности и родам и в отпуске по уходу за ребенком до достижения им возраста трех лет (аттестация возможна не ранее чем через год после выхода из отпуска); замещающие должности гражданской службы категорий «руководители» и «помощники (советники)», с которыми заключен срочный служебный контракт (за исключением гражданских служащих, замещающих отдельные должности гражданской службы, назначение на которые и освобождение от которых осуществляются Президентом Российской Федерации или Правительством Российской Федерации, необходимость аттестации которых предусмотрена соответственно указом Президента Российской Федерации или постановлением Правительства Российской Федерации); в течение года со дня сдачи квалификационного экзамена.

По результатам аттестации комиссия принимает решение о соответствии либо несоответствии государственного служащего замещаемой должно- 
сти, признании его соответствующим замещаемой должности и рекомендации к включению в кадровый резерв для замещения вакантной должности гражданской службы в порядке должностного роста либо о признании его соответствующим замещаемой должности при условии получения дополнительного профессионального образования.

Учитывая изложенное, механизм внеочередной аттестации будет скорее использоваться представителем нанимателя при реорганизации государственного органа, предусматривающей сокращение должностей гражданской службы, но не в случае упразднения государственного органа.

По результатам внеочередной аттестации гражданским служащим, имеющим преимущественное право на замещение должности гражданской службы, могут быть предоставлены для замещения иные должности гражданской службы, в том числе в другом государственном органе.

В соответствии с ч. 4 ст. 31 № 79-Ф3 к факторам, влияющим на наличие преимущественного права, относятся более высокая квалификация, соответствие специальности, направлению подготовки области и виду профессиональной деятельности государственного служащего, большая продолжительность стажа гражданской службы или работы по специальности, направлению подготовки, а также более высокие результаты профессиональной служебной деятельности. Необходимо отметить, что с учётом ст. 73 № 79-Ф3, а также п. 30 постановления Пленума Верховного Суда Российской Федерации от 17.03.2004 г. № 2 «О применении судами Российской Федерации Трудового кодекса Российской Федерации», нормы аналогичной статьи 179 Трудового кодекса («Преимущественное право на оставление на работе при сокращении численности или штата работников»), к правоотношениям по определению преимущественного права на замещение должности гражданской службы не применяются. При этом в соответствии со ст. 21 Закона Российской Федерации от 21.07.1993 г. № 5485-1 «О государственной тайне» для лиц, допущенных к государственной тайне на постоянной основе, устанавливается преимущественное право при прочих равных условиях на оставление на работе в случае проведения организационно-штатных мероприятий

Действенным механизмом обеспечения сохранения кадрового состава является предусмотренная законодательством норма о необходимости предложения гражданскому служащему всех имеющихся вакантных должностей государственной службы в том же государственном органе либо в органе, который является правопреемником реорганизу- емого государственного органа. Такие вакансии должны предлагаться с учётом категории и группы замещаемой гражданским служащим должности гражданской службы, уровня его квалификации, его специальности, направления подготовки, стажа гражданской службы или работы по специальности, направлению подготовки.

Государственному служащему, должность которого сокращается, могут предлагаться как вакансии, замещение которых не предусматривает проведение конкурса, так и вакансии, замещение которых предусматривает проведение конкурса, причём в таком случае с учётом положений п. 4 ч. 2 ст. 22 № 79-Ф3 конкурс на замещение вакантной должности не проводится [2].

Законодательно п. 4 ст. 31 № 79-ФЗ также предусмотрена возможность предложения вакантных должностей в иных государственных органах. Механизм реализации данной возможности урегулирован постановлением Правительства Российской Федерации от 19 сентября 2013 г. № 822, которым утверждены Правила предоставления государственному гражданскому служащему в случае отсутствия вакантных должностей в государственном органе, в котором сокращаются должности государственной гражданской службы, или государственном органе, которому переданы функции упраздненного государственного органа, вакантной должности государственной гражданской службы в иных государственных органах.

Указанные Правила устанавливают достаточно жёсткие сроки для поиска вакантных должностей гражданской службы в иных органах (в том числе посредством Федерального портала государственной службы и кадров) - не позднее чем за 30 дней до дня предстоящего увольнения государственного служащего в связи с сокращением должности. Причём включению в список вакантных должностей государственной гражданской службы в государственных органах, предлагаемых государственному гражданскому служащему, подлежат размещенные на портале вакантные должности государственной гражданской службы, а также вакантные должности государственной гражданской службы, информация о которых получена кадровой службой государственного органа.

В список включаются должности государственной гражданской службы в иных государственных органах, расположенных как в той же местности (местности в пределах административно-территориальных границ того населенного пункта, где расположен государственный орган, в котором сокращаются должности государственной гражданской службы, или государственный орган, которому переданы 
функции упраздненного государственного органа), так и расположенных в другой местности в пределах Российской Федерации.

Уведомление о предложении государственному гражданскому служащему вакантных должностей государственной гражданской службы в иных государственных органах с приложением списка этих вакантных должностей, подписанное представителем нанимателя или уполномоченным им лицом, вручается кадровой службой государственному гражданскому служащему под роспись не позднее чем за 25 дней до дня предстоящего увольнения.

После чего государственный гражданский служащий представляет в кадровую службу в течение 2 рабочих дней со дня ознакомления с уведомлением заявление с просьбой направить его анкету в государственные органы, в которых государственным гражданским служащим выбраны вакантные должности государственной гражданской службы, или отказывается от предложенных кадровой службой вакантных должностей государственной гражданской службы.

В течение 2 рабочих дней со дня получения заявления государственного служащего кадровая служба государственного органа направляет в государственные органы письма с использованием средств факсимильной связи, электронной почты или иных средств связи, позволяющих зафиксировать факт их получения адресатом, с просьбой рассмотреть кандидатуру государственного гражданского служащего на замещение вакантной должности государственной гражданской службы и представить в государственный орган, в котором сокращаются должности государственной гражданской службы, или государственный орган, которому переданы функции упраздняемого государственного органа, соответствующую информацию.

В письме указываются выбранные государственным гражданским служащим вакантные должности государственной гражданской службы с приложением анкеты государственного гражданского служащего по форме, утвержденной распоряжением Правительства Российской Федерации от 26 мая 2005 г. № 667-р, а также дата окончания 2-месячного срока после предупреждения государственного гражданского служащего об увольнении в соответствии с частью 2 статьи 31 Федерального закона «О государственной гражданской службе Российской Федерации».

Государственный орган не позднее трёх рабочих дней рассматривает указанные материалы и направляет ответ о готовности рассмотреть кандидатуру государственного гражданского служащего, претендующего на замещение вакантной должности государственной гражданской службы, или об отказе в рассмотрении его кандидатуры с обоснованием причины. В случае готовности рассмотреть кандидатуру в ответе также указывается информация о месте, дате и времени проведения собеседования.

Указанная информация доводится до сведения государственного служащего под роспись в течение одного рабочего дня, следующего за днём поступления информации. При этом гражданский служащий самостоятельно оплачивает расходы, связанные с проведением собеседования (проезд к месту проведения собеседования и обратно, наем жилого помещения, проживание, пользование услугами средств связи и другие расходы).

По итогам собеседования кадровая служба государственного органа, в котором проводилось собеседование, не позднее 3 дней информирует кадровую службу государственного органа, направившую запрос, а последняя, в свою очередь, доводит до сведения государственного гражданского служащего поступившую информацию под роспись в течение одного рабочего дня, следующего за днем её поступления. В случае принятия положительного решения оформляется перевод государственного гражданского служащего.

В данном случае перевод на иную должность осуществляется в порядке, предусмотренном статьёй 28 № 79-Ф3. Необходимо отметить, что для государственного гражданского служащего, назначенного в порядке перевода в связи сокращением должностей гражданской службы или упразднением государственного органа, испытание не устанавливается.

В случае отказа гражданского служащего от предложенной для замещения иной должности гражданской службы, в том числе в другом государственном органе, при сокращении должностей гражданской службы или упразднении государственного органа гражданский служащий освобождается от замещаемой должности гражданской службы и увольняется с гражданской службы. В этом случае служебный контракт прекращается при сокращении должностей гражданской службы в соответствии с пунктом 8.2 части 1 статьи 37 № 79-Ф3 и при упразднении государственного органа в соответствии с пунктом 8.3 части 1 статьи 37 № 79-Ф3.

Важно отметить, что в соответствии со ст. 261 Трудового кодекса («Гарантии беременной женщине и лицам с семейными обязанностями при расторжении трудового договора») не допускается увольнение в связи с сокращением должности женщины, имеющей ребенка в возрасте до трех лет, одинокой матери, воспитывающей ребенка-инвалида в возрасте до во- 
семнадцати лет или малолетнего ребенка - ребенка в возрасте до четырнадцати лет, другого лица, воспитывающего указанных детей без матери, родителя (иного законного представителя ребенка), являющегося единственным кормильцем ребенка-инвалида в возрасте до восемнадцати лет либо единственным кормильцем ребенка в возрасте до трех лет в семье, воспитывающей трех и более малолетних детей, если другой родитель (иной законный представитель ребенка) не состоит в трудовых отношениях.

Таким образом, освобождение от замещаемой должности и увольнение с гражданской службы государственного служащего будет обоснованным при наличии ряда факторов: фактического сокращения должности, отсутствия у государственного служащего преимущественного права на замещение имеющихся вакантных должностей, отсутствия обстоятельств, препятствующих увольнению, отсутствия возможности предоставления иной должности гражданской службы в том же либо ином государственном органе, соблюдения процедуры предупреждения государственного служащего.

В соответствии с ч. 3.1 ст. 37 № 79-Ф3 в случае расторжения служебного контракта в связи с сокращением должности либо упразднением государственного органа государственному служащему выплачивается компенсация в размере четырёхмесячного денежного содержания. При этом выходное пособие не выплачивается.

Гражданскому служащему, увольняемому из государственного органа, расположенного в районах Крайнего Севера и приравненных к ним местностях, по указанным основаниям, дополнительно выплачивается компенсация за пятый и шестой месяцы со дня увольнения по решению органа службы занятости населения при условии, что в течение одного месяца после увольнения гражданский служащий обратился в этот орган и не был им трудоустроен. Выплата указанной компенсации производится представителем нанимателя государственного органа, в котором гражданский служащий замещал должность гражданской службы, за счет средств государственного органа.

Статья 50 № 79-Ф3 предусматривает, что денежное содержание состоит из месячного оклада гражданского служащего в соответствии с замещаемой им должностью гражданской службы и месячного оклада гражданского служащего в соответствии с присвоенным ему классным чином гражданской службы, которые составляют оклад месячного денежного содержания гражданского служащего, а также из ежемесячных и иных дополнительных выплат, к которым относятся ежемесячная надбавка к должностному окладу за выслугу лет, ежемесячная надбавка к должностному окладу за особые условия гражданской службы, ежемесячная процентная надбавка к должностному окладу за работу со сведениями, составляющими государственную тайну, премия за выполнение особо важных и сложных заданий, ежемесячное денежное поощрение, а также единовременная выплата при предоставлении ежегодного оплачиваемого отпуска и материальная помощь.

Необходимо отметить, что в соответствии с п. 3 ст. 217 Налогового кодекса и п. 2 ч. 1 ст. 9 Федерального закона от 24.07.2009 г. № 212-Ф3 «О страховых взносах в Пенсионный фонд Российской Федерации, Фонд социального страхования Российской Федерации, Федеральный фонд обязательного медицинского страхования» не подлежат налогообложению и обложению страховыми взносами все виды установленных действующим законодательством Российской Федерации, законодательными актами субъектов Российской Федерации, решениями представительных органов местного самоуправления компенсационных выплат, в том числе связанных с увольнением работников.

В случае если государственному служащему, должность которого подлежит сокращению, в том же государственном органе предложена вакантная должность, которая при этом не относится к должностям государственной службы (например, эксперт), при прекращении служебного контракта всё же должна быть выплачена компенсация в полном объёме.

Интересной также представляется ситуация, при которой гражданский служащий восстанавливается на службе в результате признания его увольнения с гражданской службы в связи с сокращением должности незаконным. В такой ситуации выплаченная компенсация в размере четырёхмесячного денежного содержания подлежит зачёту при исчислении среднего заработка за вынужденный прогул.

Представитель нанимателя с письменного согласия гражданского служащего вправе расторгнуть с ним служебный контракт до истечения срока двухмесячного периода с момента предупреждения, выплатив ему дополнительную компенсацию в размере сохраняемого денежного содержания, исчисленного пропорционально времени, оставшемуся до истечения срока предупреждения об увольнении.

Таким образом, в статье были рассмотрены особенности государственно-служебных отношений, возникающих в процессе изменения в структуре федеральных органов исполнительной власти как при создании новых органов власти, так и при сокращении должностей в реорганизуемых либо упраздняемых 
DOI: $10.7256 / 1811-9018.2016 .8 .19831$

При цитировании этой статьи сноска на dоі обязательна

Власть и управление

органах. Очевидно, что в условиях финансово-экономического кризиса постоянно предпринимаются усилия по оптимизации действующего аппарата государственного управления. Процесс проведения организационно-штатных мероприятий, особенно, если он связан с сокращением должностей государственной службы либо упразднением государственного органа, неизбежно связан обжалованием действий представителя нанимателя в суде [3]. Указанное обстоятельство диктует необходимость комплексного понимания, систематизации и корректного применения законодательства о государственной службе.

\section{Библиография:}

1. Занко Т.А. Формы реорганизации в системе и структуре федеральных органов исполнительной власти // Право и политика. - 2015. - № 9. - С. 1239-1244

2. Пресняков М.В. Государственные гарантии гражданскому служащему при увольнении в связи с организационноштатными мероприятиями: к вопросу о реализации конституционных принципов равенства и справедливости в правовом регулировании государственно-служебных отношений // Трудовое право. - 2009. - № 12. - С. 88

3. Гладких С.Н. Реорганизация как способ увольнения государственного служащего // Адвокат. 2012. N 9. С. 50.

4. Железнякова Е.А. Государственная служба как социально-правовой институт: гарантии государственных служащих // Административное и муниципальное право. - 2015. - 10. - С. 1015 - 1021. DOI: 10.7256/1999-2807.2015.10.15079.

\section{References (transliterated):}

1. Zanko T.A. Formy reorganizatsii v sisteme i strukture federal'nykh organov ispolnitel'noi vlasti // Pravo i politika. - 2015. № 9. - S. 1239-1244

2. Presnyakov M.V. Gosudarstvennye garantii grazhdanskomu sluzhashchemu pri uvol'nenii v svyazi s organizatsionno-shtatnymi meropriyatiyami: $\mathrm{k}$ voprosu o realizatsii konstitutsionnykh printsipov ravenstva i spravedlivosti v pravovom regulirovanii gosudarstvenno-sluzhebnykh otnoshenii // Trudovoe pravo. - 2009. - № 12. - S. 88

3. Gladkikh S.N. Reorganizatsiya kak sposob uvol'neniya gosudarstvennogo sluzhashchego // Advokat. 2012. N 9. S. 50.

4. Zheleznyakova E.A. Gosudarstvennaya sluzhba kak sotsial'no-pravovoi institut: garantii gosudarstvennykh sluzhashchikh // Administrativnoe i munitsipal'noe pravo. - 2015. - 10. - C. 1015 - 1021. DOI: 10.7256/1999-2807.2015.10.15079. 